Conclusion: Although pANCA is thought to be associated with ILD or pulmonary fibrosis, we detected equal numbers of $c$ and pANCA in a well characterised population of ILD patients. Approximately one quarter of patients with $p$ or cANCA had an MDT diagnosis of ANCA-associated vasculitis. The clinical and CT characteristics did not differ between $\mathrm{C}$ and pANCA ILD patients. The two-year mortality of patients with ANCA and ILD was significant ( $22 \%$ in CANCA-ILD and $16 \%$ in pANCA). In surviving patients, the FVC and DLCO improved over a 24-month period.

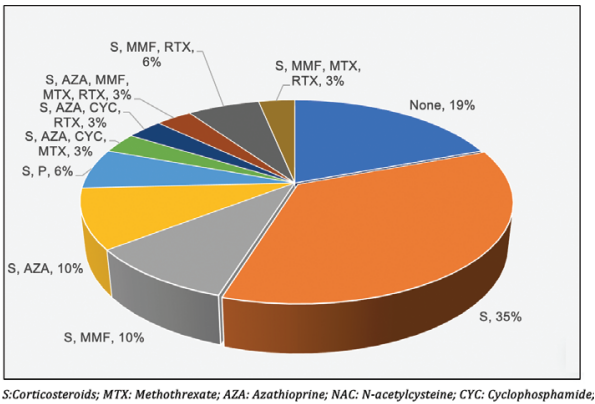

S:Corticosteroids; MTX: Methothrexate; AZA: Azathioprine;
RTX: Rituximab; P: Pirfenidone; MMF: Mycofenolate mofetil

Figure 1 Distribution of treatments used for CANCA patients over study period

Figure 1

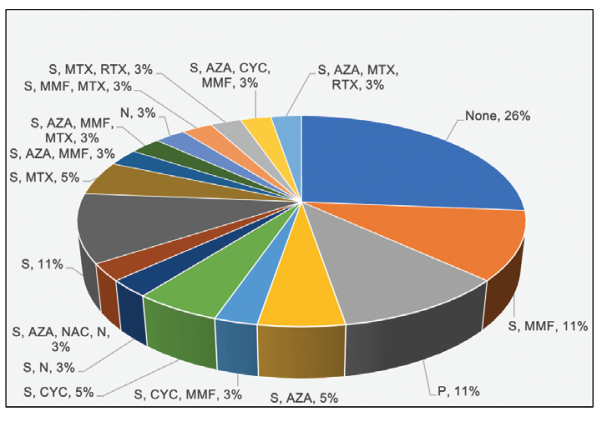

S: Corticosteroids; MTX: Methothrexate; AZA: Azathioprine; NAC: N-acetylcysteine; CYC: Cyclophosphamide RTX: Rituximab; P: Pirfenidone; N: Nintedanib; MMF: Mycofenolate mofetil

Figure 2 Distribution of treatment used in pANCA patients over study period

Figure 1

Disclosure of Interests: None declared

DOI: 10.1136/annrheumdis-2019-eular.6254

\section{AB0594 THE CLINICAL SPECTRUM OF HENOCH-SCHÖNLEIN PURPURA IN CHILDREN: A PROSPECTIVE SINGLE- CENTER STUDY}

Şerife Gül Karadağ, Hafize Emine Sonmez, Ayşe Tanatar, Mustafa Çakan, Figen Çakmak, Nuray Aktay Ayaz. University of Health Science, Kanuni Sultan Süleyman Research and Training Hospital, Pediatric Rheumatology, Istanbul, Turkey

Background: Henoch-Schönlein purpura (HSP) is the most common vasculitis of children. Predicting the risk factors at the time of diagnosis for systemic involvement may facilitate the management of the disease.

Objectives: The aim of this study is to evaluate the demographic and clinic findings of patients with HSP and also to determine predictive factors for assessing the development of gastrointestinal system (GIS) and renal involvement.

Methods: This study was performed prospectively among children with HSP who are under 18 years of age and being followed-up in the Pediatric Rheumatology Unit of Health Sciences University Kanuni Sultan Süleyman Training and Research Hospital between January 2016 and January 2018.

Results: A total of 265 patients, 137 boys (51.7\%) and 128 girls (48.3\%) were involved to the study. The mean \pm standard deviation of age at the diagnosis was $7.5 \pm 3.2$. The most common disease onset season was spring $(31.7 \%)$. The rate of arthritis, GIS involvement and renal involvement was $54 \%, 51.3 \%$ and $29.1 \%$ respectively. GIS bleeding was more frequent in males than females $(p=0.007)$. Boys over 7 years of age had significantly more common GIS bleeding $(p=0.04)$. Intussusception, relapse and serious GIS involvement requiring hospitalization and steroid treatment were highly associated with severe renal involvement.

Conclusion: Intussusception, relapse and serious GIS involvement requiring hospitalization and steroid treatment were highly associated with severe renal involvement. We recommend at least 2 years follow-up for not overlooking renal involvement of HSP

\section{REFERENCES}

[1] Yang YH, Hung CF, Hsu CR, Wang LC, Chuang YH, Lin YT, Chiang BL (2005) A nationwide survey on epidemiological characteristics of childhood Henoch-Schonlein purpura in Taiwan. Rheumatology (Oxford) 44 (5):618622. doi:10.1093/rheumatology/keh544

[2] Wang K, Sun X, Cao Y, Dai L, Sun F, Yu P, Dong L (2018) Risk factors for renal involvement and severe kidney disease in 2731 Chinese children with Henoch-Schonlein purpura: A retrospective study. Medicine (Baltimore) 97 (38):e12520. doi:10.1097/MD.0000000000012520

Acknowledgement: None

Disclosure of Interests: None declared

DOI: 10.1136/annrheumdis-2019-eular.1999

\section{AB0595 THE USEFULNESS OF 18F-FLUORODEOXYGLUCOSE POSITRON EMISSION TOMOGRAPHY CT (18F-FDG PET/ CT) AS AN IMAGING BIOMARKER IN TAKAYASU ARTERITIS TREATED WITH TOCILIZUMAB}

Mikiya Kato ${ }^{1,1}$, Hanae Okuda ${ }^{2}$, Tomohiro Kameda ${ }^{1}$, Taichi Miyagi $^{1}$, Risa Wakiya ${ }^{1}$, Shusaku Nakashima ${ }^{1}$, Hiromi Shimada ${ }^{1}$, Mai Mahmoud Fahmy Mansour ${ }^{1}$, Yuka Yamamoto' ${ }^{2}$ Hiroaki Dobashi'. ' ${ }^{1}$ Kagawa university, Division of Hematology, Rheumatology and Respiratory Medicine, Kagawa, Japan; ${ }^{2}$ Kagawa university, Department of Radiology, Kagawa, Japan

Background: Disease activity in large vessel vasculitis (LVV) including TAK is traditionally assessed by clinical and serological (ESR, CRP) parameters. Imaging assessment, including FDG-PET, may also be useful to monitor LVV. On the other hand, Tocilizumab (TCZ) treatment showed a favorable trend toward refractory Takayasu arteritis (TAK) (1). Because the TCZ could suppress the CRP or ESR elevation strongly despite the exist of TAK disease activity, clinical and serological (ESR, CRP) parameters could not reflect the disease activity of TAK appropriately.

Objectives: This study objective was to determine the efficacy of $18 \mathrm{~F}$ FDG PET/CT on the evaluating the disease activity of TAK treated TCZ compared with clinical and serological parameters.

Methods: Five Patients with TAK were recruited into a prospective, observational cohort. All patients in this study underwent FDG-PET/CT scans at $6-12$ month intervals before and after TCZ treatment. Serological (ESR, CRP) and clinical assessment were determined at each visit. Disease activity was determined whether scans were active or inactive based on visual inspection of arterial 18F-FDG uptake. To determine the score of arterial FDG uptake assessed qualitatively relative to liver activity in 10 vascular beds with higher scores indicating more vascular inflammation. Additionally, scoring of FDG uptake was conducted to caluculate as divided into 4 grade compared with liver activity: 0 , no uptake present; I, low-grade uptake (uptake present but lower than liver uptake); II, intermediate-grade uptake (similar to liver uptake); III, high-grade uptake (higher than liver uptake) (2). Clinical and imaging assessments were performed blinded to each other.

Results: All 5 cases (one male and 4 female) were initiated by TCZ treatment. The average age was $42.2 \pm 11.6$ years old. The disease duration at the administration of TCZ was $176 \pm 136$ months. The mean dos age of PSL was $6.40 \pm 3.72 \mathrm{mg} /$ day. After initiating TCZ treatment, mean CRP values decreased from $1.44 \pm 1.80$ to $0.032 \pm 0.034$, and the PSL dose was reduced to $4.00 \pm 2.61 \mathrm{mg} /$ day. No serious adverse events were observed. Though serum level of inflammatory biomarker such as CRP or ESR had become into normal range in all patients, arterial 18F-FDG uptake also remained in all patients after TCZ treatement. Additionally, clinical manifestations were correlate with site numbers and score of FDG uptake. The change of FDG score could reflect the improvement of clinical manifestation compared than serological biomarkers.

Conclusion: Serological biomarker such as CRP or ESR could not reflect disease activity appropriately in TAK patients treated with TCZ. 18F-FDG $\mathrm{PET} / \mathrm{CT}$ was more useful for evaluating disease activities in Takayasu arteritis treated with TCZ. Further study might be needed to determine the definition of complete remission in TAK patients treated with TCZ.

\section{REFERENCES}

[1] Nakaoka Y, Isobe M, Takei S, et al. Ann Rheum Dis 2018;77:348-354 
[2] Ingo Einspieler, et al. Eur J Nucl Med Mol Imaging 2015 42:1012-1024

[3] Quinn KA, et al. Ann Rheum Dis 2018;77:1166-1172.

Disclosure of Interests: None declared

DOI: 10.1136/annrheumdis-2019-eular.4429

\section{AB0596 ASSESMENT OF DAMAGE IN TAKAYASU ARTERITIS PATIENTS WITH VASCULITIS DAMAGE INDEX (VDI) AND TAKAYASU ARTERITIS DAMAGE SCORE (TADS)}

Sema Kaymaz Tahra, Fatma Alibaz-Oner, Haner Direskeneli. Marmara University Faculty of Medicine, Division of Rheumatology, Istanbul, Turkey

Background: Evaluation of damage in patients with takayasu arteritis is important because of the mortality and morbidity burden caused by the disease. Damage can be associated with treatment or with the disease itself (1).

Objectives: In this study we aimed to evaluate the damage in our Takayasu arteritis patients by using VDI and TADS scores.

Methods: Takayasu arteritis patients fullfilling the ACR 1990 criteria and had $>3$ months follow-up were enrolled in this study. TADS and VDI scores calculated at the end of the follow-up evaluated and compared. Results: 114 patients (F/M: 101/13) were included in the study. The mean age at diagnosis, median symptom duration at baseline visit and mean follow-up duration were $35.3 \pm 13.3$ years, 12 (0-360) months and $76.9 \pm 51.4$ months respectively. Mean VDI score was $5.1 \pm 2.5$ and mean TADS score was 7.9 \pm 3.5 . At least one disease-related damage item was present in all of the patients for both VDI and TADS meanwhile $\geq 1$ treatment-related damage item was established in 69 (66.1\%) patients with VDI and 46(40.7\%) patients with TADS scoring system. Median treatment related-item number was $1(0-6)$ in VDI and $0(0-3)$ in TADS. This difference may be due to the lack of disease-related parameters such as diabetes, cataract, osteoporosis, avascular necrosis in TADS. The median number of disease-related items was higher in TADS scoring (4 items vs 8 items). TADS scores include more detailed and higher number of items under vascular intervention and pulse loss categories. Also bruit and systolic hypertension data is only available in TADS(Table1)

There was no significant difference between patients with relapsing disease and patients with no relapses for both TADS and VDI scores. There was a weak corelation between VDI and cumulative steroid dose $(p=0.002, \quad r=0.32)$, and VDI-disease duration $(p=0.001, r=0.29)$. A weak corelation between TADS and disease duration was established $(p=0.04$ $r=0.19$ ). No corelation was detected for TADS and cumulative steroid dose.

Conclusion: In Takayasu arteritis, detecting the disease-related and treatment-related part of damage must be considered while monitoring the disease. VDI seems to be predominant evaluating the treatment-related damage. TADS provides more detailed information on disease-related damage.

\section{REFERENCES}

[1] Omma A., Erer B., Karadag O.et al. (2017). Remarkable damage along with poor quality of life in Takayasu arteritis: cross-sectional results of a long-term followed-up multicentre cohort. Clin Exp Rheumatol., 35, 77-82.

Table 1. Comparison of VDI and TADS scores in our Takayasu patients

\begin{tabular}{lcc}
\hline Categories & VDI & TADS \\
& $\mathrm{n}(\%)$ & $\mathrm{n}(\%)$ \\
\hline Musculoskeletal & $23(20)$ & - \\
Osteoporosis & $15(13.6)$ & \\
Avascular necrosis & $6(5.4)$ & - \\
Skin & $14(12.6)$ & $8(7.1)$ \\
Ocular & $37(33.3)$ & - \\
Cataract & $11(9.9)$ & - \\
Retinal change & $19(17.1)$ & $8(7.1)$ \\
Visual impairment/diplopia & $14(12.6)$ & - \\
ENT & $1(0.8)$ & $16(14.2)$ \\
Pulmonary & $20(18)$ & $114(100)$ \\
Cardiovascular & $79(71.2)$ & $92(81.4)$ \\
Bruit & - & $79(69.9)$ \\
Pulse loss & - & - \\
Valvular diasease & $44(39.6)$ & $18(15.9)$ \\
Ischemic cardiac pain & - & - \\
Myocardial infarction & $8(7.2)$ & $27(23.9)$ \\
Aortic Incompetence & - & - \\
Diastolic BP > 95 & $46(40.7)$ &
\end{tabular}

Peripheral vascular disease

Absent pulses in one limb

Claudication > 3 months

Major/minör tissue loss

Venous thrombosis

Gastrointestinal

Renal

Diastolic BP > 95

Neuropsychiatric

Vascular Intervention

Other

Malignancy

Infertility

Diabetes

$110(99.1)$

$78(70.3)$

$89(80.2)$

$1(0.9)$

$1(0.9)$

$3(2.7)$

4 (3.6)

$47(41.6)$

$46(40.7)$

18 (16.2)

-

$13(11.7)$

$2(1.8)$
$1(0.9)$

$8(8.1)$

$14(12.4)$

$45(39.6)$

$14(12.4)$

$2(1.8)$

$1(0.9)$

VDI: Vasculitis Damage Index

TADS: Takayasu Arteritis Damage Score

ENT: Eye-Nose-Throat

"- this item is not included in this scoring system

'- ' this item is categorized in another category in the scoring system mentioned

Disclosure of Interests: None declared

DOI: 10.1136/annrheumdis-2019-eular.6025

\section{AB0597 CAN A ONE-HOUR QUANTITATIVE ASSESSMENT OF FDG-PET-CT (MODIFIED-PETVAS) BE USEFUL IN TAKAYASU'S ARTERITIS?}

Sema Kaymaz Tahra ${ }^{1}$, Salih Özgüven ${ }^{2}$, Ali Ugur Unal ${ }^{1}$, Fatma Alibaz-Oner ${ }^{1}$, Tunc Ones ${ }^{2}$, Tanju Yusuf Erdil ${ }^{2}$, Haner Direskeneli ${ }^{1} .{ }^{1}$ Marmara University Faculty of Medicine, Department of Internal Medicine, Division of Rheumatology, Istanbul, Turkey, ${ }^{2}$ Marmara University Faculty of Medicine, Department of Nuclear Medicine, Istanbul, Turkey

Background: FDG-PET-CT is suggested as an imaging method for the assessment of disease activity in Takayasu's arteritis (TAK). Recently PETVAS, a quantitative score assessed at 2-hours is suggested as an imaging tool for TAK (1). However, most studies with FDG-PET-CT in the literature is performed at one-hour, similar to suggested as the minumum time in recent EULAR recommendations for the use of imaging in large-vessel vasculitis (2).

Objectives: In this study, we aimed to evaluate the value of a modified PET Vascular Activity Score (PETVAS) (performed at one-hour) during the initial diagnosis and follow-up of TAK patients.

Methods: Patients who are diagnosed with Takayasu's arteritis and underwent FDG-PET-CT imaging during their follow-up were evaluated in this study retrospectively. FDG-PET-CT imaging was performed at the first hour of FDG uptake. Demographic and clinical characteristics of the patients were recorded from patients' charts. Physician's Global Assessment (PGA) was used to determine clinical activity. In the modified PETVAS scoring system, 9 arterial areas (Ascending Aorta, Aortic Arch, Descending Thoracic Aorta, Abdominal Aorta, Right Carotid Artery, Left Carotid Artery, Innominate Artery, Right Subclavian Artery, Left Subclavian Artery) were scored between 0 and 3 according to the FDG uptake, as originally suggested. The degree of arterial involvement was scored as $0=$ no uptake, $1=$ less than liver involvement, $2=$ equal involvement to liver $3=$ greater than liver involvement (maximum score $=27$ ). The visual analysis using the liver FDG uptake as the reference was also assessed and compared with m-PETVAS score.

Results: Thirty-eight imagings of 28 patients $(F / M=22 / 6$, mean age $=39,7 \pm$ 14,8 years) were evaluated. Median CRP level was 16,7 (2-126) $\mathrm{mg} / \mathrm{L}$. Median m-PETVAS score was $5(0-27)$ and m-PETVAS was significantly higher in patients who were accepted as active according to PGA (median PETVAS score 6,0 vs $1,5, p=0.03$ ). Similarly, patients who have an active PET assessed with only visual analysis (VA) have higher $m$ PETVAS scores than patients who were VA inactive (median score 9,0 vs $2,5, p=0.000)$. A positive correlation was observed between the CRP levels before imaging and total m-PETVAS scores $(p=0.01$, rho $=0.52)$. In $35 / 38$ imaging assessments the score was $>0$ and the immunosuppressive agent was changed in $24(63 \%)$ of these patients. Twenty-seven patients received corticosteroids before imaging. No difference in PETVAS scores were present between patients who were taking steroids vs nonsteroid use. In 11 patients (29\%), PET involvement other than the 9 arterial areas used for assessing the score, were observed. The mean age of this group was higher than the rest of the group $(47,2 \pm 14,7$ vs 35,7 $\pm 11,2$ years).

Conclusion: FDG-PET-CT assessment with a modified PETVAS (assessed at one hour) demonstrated higher scores in patients with Takayasu's 